\title{
Treatment of cervical intraepithelial neoplasia in outpatient practice
}

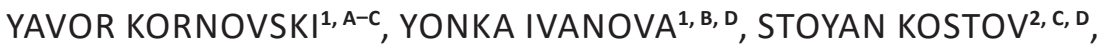 \\ STANISLAV SLAVCHEV ${ }^{1, A}$, F, ANGEL YORDANOV ${ }^{3, D}$, E \\ ORCID ID: 0000-0002-7719-382X
}

${ }^{1}$ Obstetrics and Gynaecology Clinic, Medical University - Varna, St. Anna University Hospital - Varna, Bulgaria

${ }^{2}$ Obstetrics and Gynaecology Clinic, St. Anna University Hospital - Varna, Bulgaria

${ }^{3}$ Department of Gynaecologic Oncology, Medical University Pleven, Pleven, Bulgaria

A - Study Design, B - Data Collection, C - Statistical Analysis, D - Data Interpretation, E - Manuscript Preparation, F - Literature Search, G - Funds Collection

Summary Background. The treatment of CIN is based on two criteria: colposcopic assessment of the altered area and histological verification - the presence and degree of dysplasia are histological diagnoses.

Objectives. To present some destructive (cryodestruction, $\mathrm{CO}_{2}$ laser vaporisation, radiofrequency ablation) and excisional (LLETZ/ /SWETZ) treatment techniques for cervical intraepithelial neoplasia (CIN), their selection criteria and application in outpatient practice. Material and methods. This is a retrospective study over a period of one year, which included 101 patients with histologically verified CIN. The diagnosis was made after targeted biopsy under colposcopic control or through a see-and-treat strategy. The following methods were applied: video colposcopy, $\mathrm{CO}_{2}$ laser vaporisation using video colposcopy, cryodestruction, LLETZ (SWETZ) under video colposcopic control.

Results. Destruction treatment was administered to 46 patients (45.5\%). Excision therapy was performed on 55 patients $(54.5 \%)$. CO laser vaporisation was performed on 20 (43.5\%) of the patients with destructive treatment, cryodestruction - on 20 (43.5\%), and radiofrequency ablation - on 6 (13\%) patients. All patients on excision therapy underwent the LLETZ procedure. After a median follow-up of 2.5 years, no high grade squamous intraepithelial lesion (HGSIL) recurrence was observed.

Conclusions. The characteristics of the altered area, the squamous-cylindrical epithelium border and degree of CIN's are decisive for the choice of treatment method - destruction or excision. The role of colposcopy, in this respect, is essential. CINs are successfully treated in an outpatient setting by destructive ( $\mathrm{CO}_{2}$ laser vaporisation, cryodestruction) and excisional methods (LLETZ, SWETZ). Key words: colposcopy, radiofrequency ablation, lasers, therapeutics.

Kornovski Y, Ivanova Y, Kostov S, Slavchev S, Yordanov A. Treatment of cervical intraepithelial neoplasia in outpatient practice. Fam Med Prim Care Rev 2021; 23(3): 313-317, doi: https://doi.org/10.5114/fmpcr.2021.108196.

\section{Background}

The treatment of cervical intraepithelial neoplasia (CIN) is based on two criteria: colposcopic assessment of the altered area and histological verification - the presence and degree of dysplasia are confirmed by histopathological examination [1-3].

\section{Colposcopic criteria for treatment of CIN}

Colposcopy plays a central role in determining the treatment of precancerous lesions: the transformation zone (TZ) is where CIN occurs [4]. Treatment decision is made individually, based on a colposcopic assessment of the atypical lesion. Three characteristics of the lesion were evaluated [4-6]:
1. Boundaries and size of the abnormal lesion - the larger the lesion, the more likely it is to be a high-grade lesion and to have glandular involvement.

2. Glands are affected.

3. The endocervix is involved.

Depending on the boundaries of the lesion and endocervix involvement, there are 3 types of lesions $[7,8]$ :

- Type 1 - Entirely ectocervical lesion. This type is suitable for destruction and excision (Figure 1A).

- $\quad$ Type 2 - The lesion has an endocervical component but is entirely visible. Both destruction and excision are possible (Figure 1B).

- Type 3 - The lesion has an endocervical component, but the upper border is not visible. Excision is performed for such types of lesions (Figure 1C).
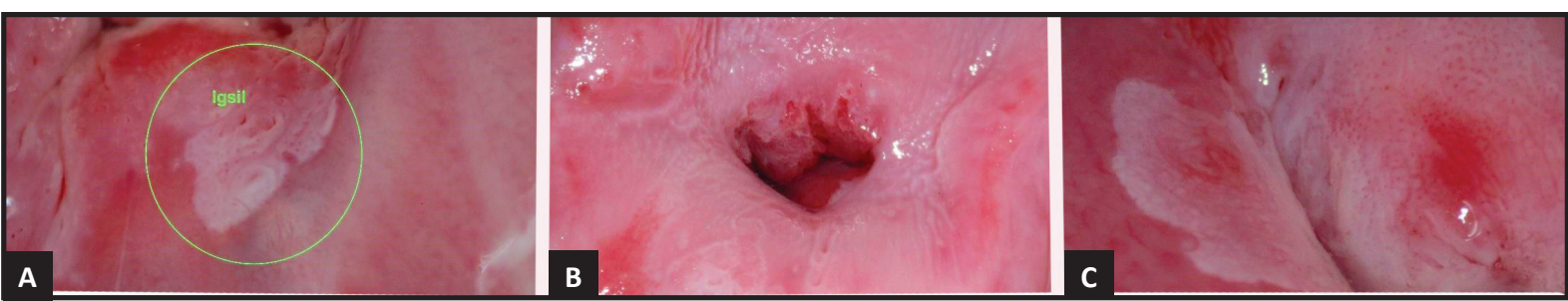

Figure 1. A. Type 1 lesion: the lesion is entirely visible, only the exocervix is involved; B. Type 2 lesion: the lesion is entirely visible, the endocervix is involved; $C$. Type 3 lesion: the lesion border is not visible in the cervical canal 

ment

Histological criteria for determining the type of CIN treat-

1. When $\mathrm{CIN} 1 /$ low grade squamous intraepithelial lesion (LGSIL) is established, there are two options: observation or treatment. Low-grade lesions tend to regress, and many guidelines recommend monitoring them by cytology and colposcopy at six-month intervals. If the colposcopic finding persists for more than 12 months, treatment becomes necessary (with exceptions for pregnancy and patients up to 24 years of age) [3].

2. Treatment is recommended for patients diagnosed with CIN 2, 3 - high grade squamous intraepithelial lesion (HGSIL) [3].

Treatment options for HGSIL have changed over the last several decades, and ablative techniques have displaced surgical procedures [9].

Methods for treatment of cervical precancerous lesions

Two groups of treatment methods are used: destructive and excisional [10-17].

Destructive methods of treating $\mathrm{CIN}$ include:

1. Cryodestruction [10],

2. Cold coagulation [13],

3. Electrocoagulation,

4. $\mathrm{CO}_{2}$ laser vaporisation $[11,12]$.

Excisional treatment methods include:

1. Conisation, which in turn can be:

- laser cone biopsy [14];

- $\quad$ scalpel conisation (cold knife biopsy) [14]

2. Loop electrosurgical excision of the transformation zone. This technique may have some variations and modifications [15-17]:

- $\quad$ LLETZ - large loop excision of transformation zone;

- LEEP - loop electrosurgical excision procedure;

- NETZ - needle excision of transformation zone;

- SWETZ - straight wire excision of the transformation zone.

3. Hysterectomy - abdominal, vaginal, laparoscopic, robotic.

General indications for application of excision techniques $[16,17]$ :

1. The lesion enters the cervical canal, and colposcopic or biopsy assessment is not possible (unsatisfactory colposcopy).

2. Cytology raises repeated suspicion of invasion without colposcopic data for such an invasion.

3. Suspicion of an invasive lesion based on colposcopy, cytology or biopsy data.

4. Abnormal glandular lesion verified by cytology or colposcopy.

5. Cytology confirms a more serious finding compared to colposcopy or pinch biopsy.

6. Endocervical curettage suggests dysplasia or carcinoma.

The diagnosis and treatment of precancerous conditions of the cervix are mandatory in order to prevent cervical cancer (CC). Diagnostic and treatment methods are suitable for outpatient use, which makes them, on the one hand, cost-effective and, on the other hand, more convenient and acceptable to patients.

\section{Objectives}

From this perspective, we aim to present some destructive (cryodestruction, $\mathrm{CO}_{2}$ laser vaporisation) and excisional (LLETZ/ /SWETZ) treatment methods of CIN, their selection criteria and applicability in outpatient practice.

\section{Material and methods}

\section{Study population}

This is a retrospective study of patients with histologically confirmed CIN at Prof. Kornovski Medical Centre for the period
1 Jan. 2018 to 31 Dec. 2018. After histological diagnosis, 101 patients were included: the diagnosis was made after targeted biopsy under colposcopic control or through a see-and-treat strategy - visualisation of colposcopic atypia and its direct excision. The following inclusion and exclusion criteria were used (Table 1).

\begin{tabular}{|l|l|}
\hline \multicolumn{2}{|l|}{ Table 1. Inclusion and exclusion criteria } \\
\hline Inclusion criteria & Exclusion criteria \\
\hline $\begin{array}{l}\text { CIN1 - after colposcopic atypia } \\
\text { persistence over 12 months }\end{array}$ & Under 24 years of age \\
\hline $\begin{array}{l}\text { Histologically confirmed CIN2- } \\
\text { 3/HGSIL }\end{array}$ & Pregnancy \\
\hline $\begin{array}{l}\text { Non-clearly visible borders of } \\
\text { the colposcopically atypical } \\
\text { area in the cervical canal - type } \\
3 \text { cervical lesion }\end{array}$ & Persistence of CIN 1 less than \\
\hline $\begin{array}{l}\text { Double abnormal cytology } \\
\text { in normal or unsatisfactory } \\
\text { colposcopy }\end{array}$ & Suspicion of invasiveness \\
\hline Informed consent & Pelvic inflammatory disease \\
\hline
\end{tabular}

\section{Methods used}

- Video colposcopy,

- $\mathrm{CO}_{2}$ laser vaporisation under video colposcopic control,

- Cryodestruction

- $\quad$ LLETZ (SWETZ) under video colposcopic control.

Features of the LLETZ procedure

The LLETZ procedure is performed under video colposcopic control, thus visualising the borders of the atypical lesion of the exocervix. We used a straight wire excision of the transformation zone (SWETZ), which provides both cutting and coagulation with excellent control over bleeding during the procedure. Otherwise, the intervention's visual control and precision are violated, and after cutting the fragment, haemostasis control is complicated due to ergonomic and logistical reasons. After the procedure, the surgical wound was treated with a sterile Monsal solution. We do not use gauze tamponades. We used a power source for quick evacuation of smoke, which is released during the procedure. This provides for:

- Clean operative field, precise and radically performed procedure without affecting adjacent tissues,

- Lack of "burnt" odour, which confuses patients,

- Lack of HPV-contaminated aerosols that can be inhaled by staff and patients.

In each case, loops, different in size and depth, were used, which provided optimal radicality, both in terms of the ectocervix and the endocervical canal and stroma, and no unnecessary removal of healthy tissue which would affect the anatomical and functional recovery of the cervix. The procedure was performed under local infiltration anaesthesia with Lidocaine after a scarification allergy test. The loops are subject to cleaning, disinfection and autoclaving after use. We performed radiofrequency ablation with the same type of anaesthesia. Regardless of the treatment method, all patients took Doxycycline (100 mg 2x/d) for 7 days and received $150 \mathrm{mg}$ of Diflucan once on the third day.

Selection criteria for choosing the treatment method are presented in Table 2.

Table 2. Selection criteria for a particular therapeutic approach

\begin{tabular}{|l|l|}
\hline Criteria for destruction & Excision criteria \\
\hline $\begin{array}{l}\text { Lesion type 1 - localised on the } \\
\text { ectocervix (without affecting } \\
\text { the vagina and endocervix) }\end{array}$ & $\begin{array}{l}\text { Lesions type } 2 \text { and } 3 \text { - borders } \\
\text { are not clearly visible }\end{array}$ \\
\hline $\begin{array}{l}\text { Small lesion - up to } 2.5 \mathrm{~cm} \text { or } \\
1-2 \text { quadrants of PVCU }\end{array}$ & $\begin{array}{l}\text { Lesion size greater than } 2.5 \mathrm{~cm} \\
- \text { large lesions are suspective } \\
\text { of HGSIL or microinvasion }\end{array}$ \\
\hline
\end{tabular}




\begin{tabular}{|l|l|}
\hline \multicolumn{2}{|l|}{ Table 2. Selection criteria for a particular therapeutic approach } \\
\hline Criteria for destruction & Excision criteria \\
\hline Histologically confirmed CIN & $\begin{array}{l}\text { Endocervical involvement and } \\
\text { suspicion for glandular involve- } \\
\text { ment }\end{array}$ \\
\hline No invasive cancer & Suspicion of invasive cancer \\
\hline $\begin{array}{l}\text { No pregnancy (3 m after birth } \\
\text { at the earliest) }\end{array}$ & $\begin{array}{l}\text { An inconsistency between } \\
\text { colposcopy and cytology }\end{array}$ \\
\hline
\end{tabular}

It should be noted that parity is not a criteria for choosing a therapeutic option.

The work obtained the positive opinion of the bioethics committee (YKMC-12/21).

\section{Results}

Destructive treatment was administered to 46 patients (45.5\%), excision therapy was performed on 55 patients (54.5\%), and the exact distribution is presented in Figure 2.
In patients with destructive treatment, the therapy method was randomly determined. Figure 3 shows the result immediately after $\mathrm{CO}_{2}$ laser vaporisation and two months later.

All patients undergoing excisional treatment received the LLETZ technique with wire loops of different widths and depths. Figure 4 shows the colposcopic findings before and immediately after the LLETZ procedure.

All patients tolerated the conducted treatment well, and no serious complications were observed in the group with destructive treatment. In 9 patients (19.5\%), there was slight vaginal discomfort lasting more than 20 days, with no significant difference according to the chosen method. In the patients' group subjected to excision, a mild pain was observed in 20 patients (36.36\%), and all of them were treated with Dexofen $2 \times 20 \mathrm{mg}$ orally for 24 hours.

All patients were monitored cytologically and coloposcopically at six-month intervals for a mean period of 2.5 years ( 2 to 3 years). No HGSIL recurrence was found in any of the cases.

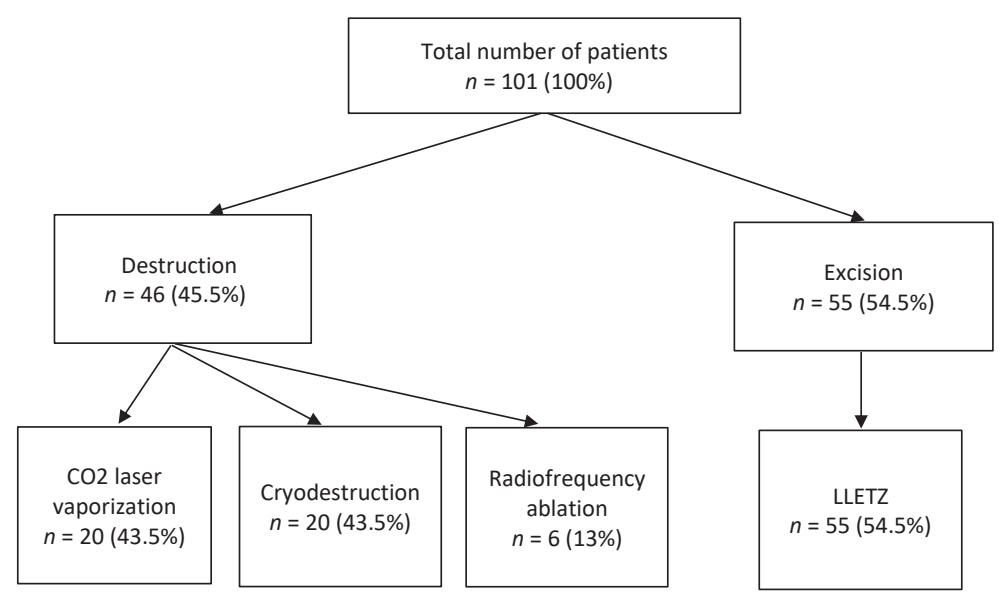

Figure 2. Distribution of patients by the type of treatment

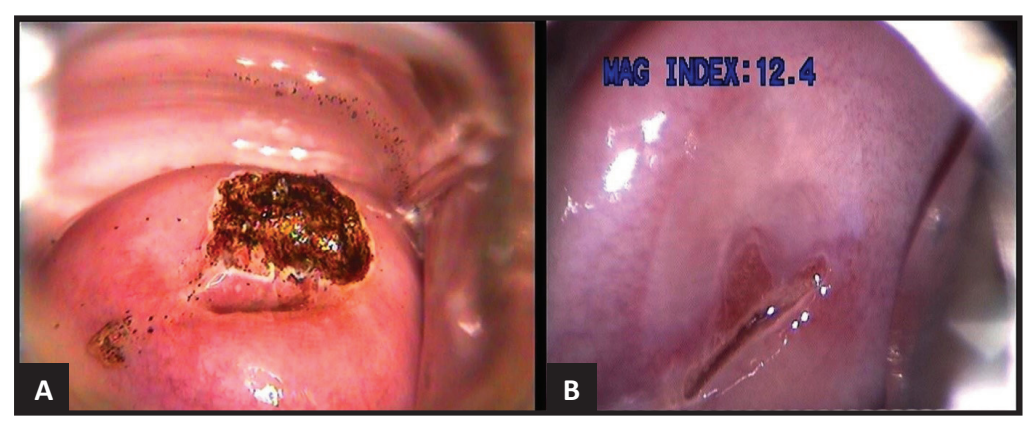

Figure 3. A. Cervix immediately after $\mathrm{CO}_{2}$ laser vaporisation; $\mathrm{B}$. The same cervix two months later

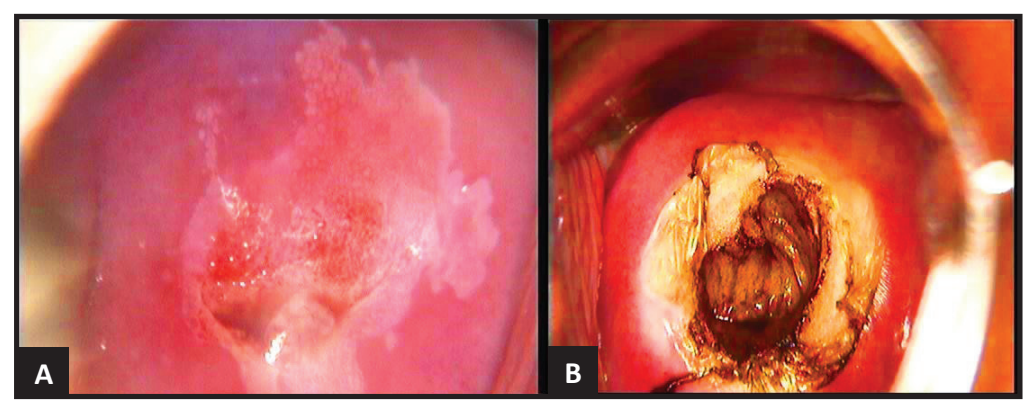

Figure 4. A. Colposcopic findings before excisional treatment; B. Colposcopic examination immediately after treatment 


\section{Discussion}

The diagnosis of preinvasive alterations of the cervix requires colposcopic examination and pinch biopsy under colposcopic control for histological verification of the most suspicious area for a high-grade lesion. The procedure is performed in an outpatient setting. Treatment of these changes can be performed by various methods (ablative/destructive and excisional). Ablative methods, such as $\mathrm{CO}_{2}$ laser vaporisation and cryodestruction, have proven their safety and applicability in an outpatient setting over time $[18,19]$. With respect to excisional methods, the LLETZ procedure has established itself as a treatment method that is not inferior to scalpel conisation in gynaecologic oncology $[20,21]$. The advantage of electric loop excision is that it can be performed in an outpatient setting under local anaesthesia $[22,23]$. This makes it more cost-effective and convenient for the patient, as it does not require hospitalisation, a hospital stay and recovery from general anaesthesia.

According to our results, treatment of preinvasive forms of cervical cancer was administered to 101 patients within one year. Destructive and excisional methods were used, with mostly colposcopic criteria for their application [4-7]. Destructive cryodestruction methods and $\mathrm{CO}_{2}$ laser vaporisation do not require anaesthesia, while the LLETZ procedure and radiofrequency ablation are performed under Lidocaine infiltration anaesthesia. Cryodestruction was performed according to the following methodology: 2 freezing sessions lasting 3 minutes with 5 minutes thawing in between. $\mathrm{CO}_{2}$ laser vaporisation and electric loop excision were performed under video colposcopic control. No intraoperative or early postoperative complications were observed. After an average of 2.5 years of follow-up, no recurrence of high-grade cervical dysplasia was observed.

\section{Conclusions}

The characteristics of the altered area, the squamous-cylindrical epithelium borders and degree of CIN's are decisive for the choice of treatment method - destruction or excision. In this respect, the role of colposcopy is essential. CIN is successfully treated in an outpatient setting using destructive ( $\mathrm{CO}_{2}$ laser vaporisation, cryodestruction) and excisional methods (LLETZ, SWETZ), and both types of treatment are safe and highly effective.

Source of funding: This work was funded from the authors' own resources.

Conflicts of interest: The authors declare no conflicts of interest.

\section{References}

1. Sehnal B, Driák D, Cibula D, et al. Tailoring surgical treatment of cervical precancerosis. J Ceska Gynekol 2014; 79(5): 372-377.

2. Sehnal B, Cibula D, Slama J. Factors influencing decisions about surgical treatment of cervical precancerous lesions. Expert Rev Anticancer Ther 2014; 14(4): 441-451.

3. Aitken CA, Siebers AG, Matthijsse SM, et al. Management and treatment of cervical intraepithelial neoplasia in the Netherlands after referral for colposcopy. Acta Obstet Gynecol Scand 2019; 98(6): 737-746.

4. Grisot C, Mancini J, Giusiano S, et al. How to optimise excisional procedures for the treatment of CIN? The role of colposcopy. Arch Gynecol Obstet 2012; 285(5): 1383-1390.

5. Santesso N, Mustafa RA, Schünemann HJ, et al. World Health Organization Guidelines for treatment of cervical intraepithelial neoplasia 2-3 and screen-and-treat strategies to prevent cervical cancer. Int J Gynaecol Obstet 2016; 132(3): 252-258.

6. Munmany M, Torné A, Nonell R, et al. Colposcopy evaluation at the time of loop electrosurgical excision procedure may avoid unnecessary treatment. J Low Genit Tract Dis 2018; 22(4): 367-374.

7. Volante R, Giubilato P, Ronco G. Quality of colposcopy and treatment - data from the national survey of Italian organised cervical screening programmes: 2006 activity. Epidemiol Prev 2009; 33(3 Suppl. 2): 75-82.

8. Boonstra H, Aalders JG, Koudstaal J, et al. Minimum extension and appropriate topographic position of tissue destruction for treatment of cervical intraepithelial neoplasia. J Obstet Gynecol 1990; 75(2): 227-231.

9. Castle PE, Murokora D, Perez C, et al. Treatment of cervical intraepithelial lesions. Int J Gynaecol Obstet 2017; 138(Suppl. 1): 20-25, doi: 10.1002/ijgo.12191.

10. Javaheri G, Balin M, Meltzer RM. Role of cryosurgery in the treatment of intraepithelial neoplasia of the uterine cervix. Obstet Gynecol $1981 ; 58(1): 83-87$.

11. Favalli G, Lomini M, Schreiber C, et al. The use of carbon-dioxide laser surgery in the treatment of intraepithelial neoplasia of the uterine cervix. UA. Prz Lek 1999; 56(1): 58-64.

12. Vetrano G, Ciolli P, Carboni S, et al. Laser vaporisation in the management of CIN. Eur J Gynaecol Oncol 2010; 31(1): 83-86.

13. Williams OE, Bodha M, Alawattegama AB. Outcome of cold coagulation for the treatment of cervical intraepithelial neoplasia in a department of genitourinary medicine. Genitourin Med 1993; 69(1): 63-65.

14. Kristensen GB Jensen LK, Hølund B. A randomised trial comparing two methods of cold knife conisation with laser conisation. Obstet Gynecol 1990; 76(6): 1009-1013.

15. Naumann RW, Bell MC, Alvarez RD, et al. LLETZ is an acceptable alternative to diagnostic cold-knife conisation. Gynecol Oncol 1994; 55(2): 224-228.

16. Kolben TM, Etzel LT, Bergauer F, et al. A randomised trial comparing limited-excision conisation to Large Loop Excision of the Transformation Zone (LLETZ) in cervical dysplasia patients. J Gynecol Oncol 2019; 30(3): e42.

17. Preaubert L, Gondry J, Mancini J, et al. Benefits of direct colposcopic vision for optimal LLETZ procedure: a prospective multicenter study. J Low Genit Tract Dis 2016; 20(1): 15-21.

18. Berget A, Andreason B, Bock J, et al. Outpatient treatment of cervical intra-epithelial neoplasia: the $\mathrm{CO}_{2}$ laser versus cryotherapy: a randomised trial. Acta Obstet Gynecol Scand 1987; 66: 531-536.

19. Berget A, Andreason B, Bock J. Laser and cryosurgery for cervical intraepithelial neoplasia. Acta Obstet Gynecol Scand 1991; 70: 231-235 .

20. Duggan B, Felix J, Muderspach L, et al. Cold-Knife conisation versus conisation by loop electrosurgical excision procedure: a randomised, prospective study. Am J Obstet Gynecol 1999; 180: 276-282.

21. Giacalone PL, Laffargue F, Aligier N, et al. Randomised study comparing two techniques of conisation: cold knife versus loop excision. J Gynecol Oncol 1999; 75(3): 356-360.

22. Yap SJ, Nathan E, Farrell L. LLETZ make it simple: anxiety, pain and treatment outcomes with outpatient large loop excision of the transformation zone under local anaesthesia. Aust N Z J Obstet Gynaecol 2020; 60(3): 438-443.

23. Borbolla Foster A, Symonds I. A comparative study of efficacy and outcomes of large loop excision of the transformation zone procedure performed under general anaesthesia versus local anaesthesia. Aust N Z J Obstet Gynaecol 2012; 52(2): 128-132. 
Tables: 2

Figures: 4

References: 23

Received: 22.04.2021

Reviewed: 25.04.2021

Accepted: 25.05.2021

Address for correspondence:

Angel Yordanov, PhD, Assoc. Prof.

Department of Gynaecological Oncology

Medical University of Pleven

Pnanayot Volov 57A Str, Pleven

Bulgaria

Tel.: +359 887671520

E-mail: angel.jordanov@gmail.com 